\title{
Guillain Barre Syndrome: A clinical observational study in Indian paediatric patients
}

*Shikha Swaroop ${ }^{1}$, Bakul B Javadekar ${ }^{2}$

Sri Lanka Journal of Child Health, 2017; 46(3): 238-242

\begin{abstract}
Background: Guillain Barre Syndrome (GBS) is the most common cause of acute flaccid paralysis (AFP) after nationwide poliomyelitis eradication measures in India. AFP surveillance has increased the detection of cases. New modalities of management such as artificial ventilation and intravenous immunoglobulin (IVIG) are expected to increase survival of GBS patients.
\end{abstract}

Objective: To study the clinical presentation, prognostic factors and outcome in GBS patients admitted to a tertiary care centre in Gujarat, India.

Method: A prospective observational study was carried out in a tertiary care centre in Gujarat, India. All paediatric patients with symmetrical onset of weakness, flaccid paralysis and hyporeflexia, admitted to the centre from March to October 2013, were included in the study. Patients with asymmetric weakness, isolated cranial nerve involvement and upper motor signs were excluded. A detailed clinical history was taken and a systemic examination was done. Nerve conduction velocity (NCV) study was carried out. All patients received IVIG and other supportive measures. Accumulated data were compared to other similar studies.

Results: Eighteen paediatric GBS patients were enrolled during the study period. An equal incidence of the disease was seen in all age groups. Males were more commonly affected. Antecedent infection was seen in $38 \%$. Upper respiratory tract infection and fever were the most common. Most (66.7\%) patients presented with weakness in both upper and lower limbs. Mortality in our study was $22 \%$. Some prognostic factors such as demyelination NCV study was seen in half of the expired patients. The greater the age the poorer was the prognosis. Patients with involvement of both upper and lower limbs at the

${ }^{1}$ UN Mehta Institute of Cardiology and Research Centre, India, ${ }^{2}$ Vadodara Medical College, India

*Correspondence: shikha_prici@yahoo.co.in

(Received on 20 December 2016: Accepted after revision on 20 January 2017)

The authors declare that there are no conflicts of interest

Personal funding was used for the project.

Open Access Article published under the Creative

Commons Attribution CC-BY License time of admission had a poorer prognosis than those with involvement of only lower limbs.

Conclusions: In our study antecedent infection was seen in $38 \%$ of patients. There was a $22 \%$ mortality and demyelination NCV study was seen in $50 \%$ of the expired patients. The prognosis was poorer in the older age groups. Patients with quadriparesis had a poorer prognosis than those with paraparesis.

DOI: http://dx.doi.org/10.4038/sljch.v46i3.8325

(Keywords: Guillain Barre Syndrome (GBS), nerve conduction velocity (NCV), intravenous immunoglobulin (IVIG), outcome)

\section{Introduction}

Guillain-Barre Syndrome (GBS) is an acute immune-mediated polyradiculoneuropathy characterized by rapidly progressive, symmetrical limb weakness with partial or complete loss of reflexes ${ }^{1}$. It may be accompanied by sensory deficits, autonomic dysfunction and respiratory insufficiency ${ }^{1}$. The clinical course comprises an acute phase, followed by a plateau phase of variable duration, leading to spontaneous recovery and resolution of paralysis to a variable degree ${ }^{1}$. Recovery can be hastened with plasma-exchange and intravenous immune-globulin (IVIG) therapy ${ }^{1}$. After control of poliomyelitis, GBS has emerged as the commonest cause of acute flaccid paralysis (AFP). The AFP surveillance system has improved the reporting of the cases. Further, the newer modalities of management made available by the government of Gujarat in the form of artificial ventilation equipment and IVIG are expected to improve the overall survival of these patients reporting to health care in Gujarat.

\section{Objectives}

- Clinical presentations in GBS patients

- Prognostic factors and outcome in terms of survival and death

- Morbidity in survivors

\section{Method}

A prospective observational study was carried out in a tertiary care centre in Gujarat state (Paediatric Department, Sir Sayajirao Gaikwad Hospital, Vadodara). Approval of the study was obtained from the Scientific and Ethical Research Committee, Medical College Vadodara. Sample size was 
decided on the basis of feasibility as it was a time bound study, so all the patients admitted to the tertiary centre from March to October 2013 were included in the study. All paediatric patients with symmetrical onset of weakness, flaccid paralysis and hyporeflexia were included. Patients with asymmetric weakness, isolated cranial nerve involvement and upper motor signs were excluded. A detailed history was taken from each patient and a central nervous system (CNS) examination was carried out. All patients received IVIG in a dose of $2 \mathrm{~g}$ per $\mathrm{kg}$ over 2 days. Nerve conduction velocity (NCV) study was done in all stable patients. As facilities for NCV study were not available in our hospital, patients were sent to the Vadodara Institute of Neurological Science for the same. Supportive care such as ventilation, intravenous (IV) fluid and antibiotics were provided as needed. CNS examination was carried out at the peak of the disease and at the time of discharge. All data obtained in the study were compared to other studies done in adults due to lack of paediatric data.

\section{Results}

Eighteen paediatric GBS patients were enrolled for the study. Of them $11(61 \%)$ were males and 07 $(39 \%)$ were females. Ages ranged from 2-12 years with equal distribution among all age groups. Antecedent events were observed in 07 (39\%) which included upper respiratory infection in 03 , fever in 03 and diarrhoea in one. The latent period between illnesses ranged from 2 to 20 days. The clinical profile is shown in Figure 1.

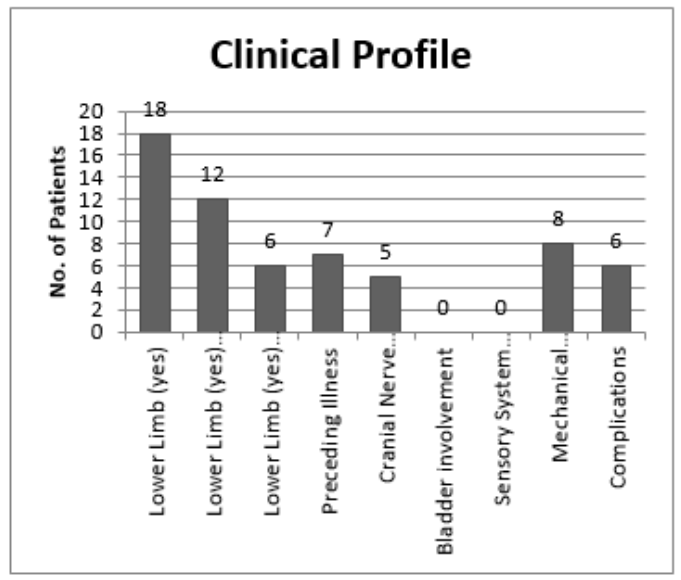

Figure 1: Clinical Profile
Whilst $12(66.7 \%)$ patients had motor weakness in all 4 limbs, $06(33.3 \%)$ had only lower limb weakness. Five $(27.8 \%)$ patients had cranial nerve involvement and $8(44.4 \%)$ had respiratory muscle involvement requiring mechanical ventilation. Sensory system involvement and bladder bowel disturbances were not reported in any of our patients. There were 04 (22\%) deaths. The details of the 4 deaths are shown in Table 1.

Table 1: Details of the 4 deaths

\begin{tabular}{|c|c|c|}
\hline $\begin{array}{c}\text { Patient } \\
\text { no. }\end{array}$ & $\begin{array}{c}\text { Mode of } \\
\text { death }\end{array}$ & $\begin{array}{c}\text { Duration of } \\
\text { hospital stay (days) }\end{array}$ \\
\hline 1 & $\begin{array}{c}\text { Sudden } \\
\text { cardiac arrest }\end{array}$ & 07 \\
\hline 2 & $\begin{array}{c}\text { Sudden } \\
\text { cardiac arrest }\end{array}$ & 06 \\
\hline 3 & $\begin{array}{c}\text { Pulmonary } \\
\text { haemorrhage }\end{array}$ & 07 \\
\hline 4 & Septic shock & 12 \\
\hline
\end{tabular}

Hospital acquired complications in the 16 GBS patients in our study are shown in Table 2.

Table 2: Hospital acquired complications $(n=16)$

\begin{tabular}{|l|c|}
\hline \multicolumn{1}{|c|}{ Complication } & No. (\%) \\
\hline Urinary tract infection & 02 \\
\hline Ventilator associated pneumonia & 02 \\
\hline Pulmonary haemorrhage & 01 \\
\hline Bed sores & 02 \\
\hline Left vocal cord palsy & 01 \\
\hline Septicaemia & 01 \\
\hline Exposure keratitis & 01 \\
\hline Pneumothorax & 01 \\
\hline Pulmonary tuberculosis & 01 \\
\hline Hypoxic brain damage & 01 \\
\hline
\end{tabular}

Left vocal cord palsy was the result of prolonged intubation. One patient who required hospitalisation for 200 days developed pulmonary tuberculosis and exposure keratitis. This same patient suffered cardiac arrest twice which resulted in irreversible hypoxic brain damage.

\section{Various possible prognostic factors}

- NCV study: Different types of NCV studies and their outcome are shown in Table 2.

Table 2: Different types of NCV study and their outcome

\begin{tabular}{|l|c|c|c|c|c|}
\hline \multicolumn{1}{|c|}{ Type of NCV study } & $\begin{array}{c}\text { Number of } \\
\text { Patients }\end{array}$ & Expired & Discharged & $\begin{array}{c}\text { Mean } \\
\text { duration of } \\
\text { stay (days) }\end{array}$ & $\begin{array}{c}\text { Median } \\
\text { duration of } \\
\text { stay (days) }\end{array}$ \\
\hline Demyelination & 06 & 02 & 04 & 10.3 & 9.5 \\
\hline AMAN + AMSAN & 09 & 0 & 09 & 39.0 & 18.0 \\
\hline
\end{tabular}

AMAN-Acute motor axonal neuropathy, AMSAN-Acute motor and sensory axonal neuropathy 
The most common type of NCV study was acute motor axonal neuropathy (AMAN) with 8 patients. Out of 4 patients who died 2 had demyelination as NCV type. We could not do NCV studies in the other two patients who died as they required mechanical ventilation since admission. One patient had mixed finding in NCV study which did not fit into any of the classified forms. Recovery was prolonged in AMAN and AMSAN variety with both mean and median duration of stay being longer (Table 2).

- $\quad$ Age: In our study mortality was more in the higher age group as shown in Table 3.

- Duration of stay in hospital: This was more in the age group 9-12 years, as shown in Table 4.
Table 3: Age and mortality

\begin{tabular}{|l|c|}
\hline \multicolumn{1}{|c|}{ Age } & No. of deaths (\%) \\
\hline 2-5 years & $0(0)$ \\
\hline 6-8 years & $02(50)$ \\
\hline 9-12 years & $02(50)$ \\
\hline Total & $04(100)$ \\
\hline
\end{tabular}

Table 4: Mean duration of hospital stay according to age group

\begin{tabular}{|l|c|}
\hline \multicolumn{1}{|c|}{ Age group } & Mean duration of stay \\
\hline 2-5 years & 12.83 days \\
\hline 6-8 years & 17.67 days \\
\hline 9-12 years & 55.17 days \\
\hline
\end{tabular}

- Weakness at the time of admission: The association between weakness at the time of admission and outcome is shown in Table 5.

Table 5: Association of weakness at the time of admission and outcome

\begin{tabular}{|l|c|c|c|}
\hline Weakness at time of admission & No. of patients & No. expired (\%) & No. discharged (\%) \\
\hline Quadriparesis & 12 & $04(33.3)$ & $08(66.7)$ \\
\hline Paraparesis & 06 & 0 & $06(100.0)$ \\
\hline
\end{tabular}

In our study all the patients who got admitted were given IVIG just after admissions.

\section{Discussion}

Studies by Rees et al, Yuan et al, and Rocha et al reported a higher percentage in males which is in accordance with our study ${ }^{2,3,4}$. However, a study by Farhoudi et al reported a higher percentage in females ${ }^{5}$. In our study, ages were uniformly distributed within an age range of 2-12 years which is not in accordance with studies by Rees et al, Italian Guillain-Barré Syndrome Study Group and Van Koningsveld et al where the incidence of GBS was found to increase with the age ${ }^{2,6,7}$. In studies by Jacobs et al and Farhoudi et al, the percentage of patients with preceding illness was $70 \%$ in comparison to $39 \%$ in our study ${ }^{5,8}$. In the study by Farhoudi et al, quadriparesis was seen in $91 \%$ and paraparesis in $07 \%$ whereas in our study $67 \%$ had quadriparesis and $33 \%$ had paraparesis ${ }^{5}$. Cranial nerve involvement was found in $41.6 \%$ in the study by Farhoudi et al, $58 \%$ in the study by Taly et al and $52 \%$ in the study by Sarkar et al compared to $27.8 \%$ in our study ${ }^{5,10,11}$. Sensory system involvement has been reported in $33 \%$ in the study by Farhoudi et al and $21 \%$ in the study by Taly et al but was not found in our study ${ }^{5,10}$. Bladder disturbances were reported in $9.1 \%$ in the study by Farhoudi et al but was not found in our study ${ }^{5}$.

Outcome in a disease like GBS is significantly influenced by early reporting of the patients, so that IVIG can be administered before the onset of respiratory paralysis and bulbar musculature involvement. Furthermore, it also depends on the quality of nursing care and long term intensive care, as patients are often bedridden and may require prolonged ventilation. In our study the mortality rate was $22 \%$ which was slightly less than the mortality rate in the study by Farhoudi et al in Iran (22.9\%) and much more than the mortality rates in studies done by Italian Guillain-Barré Syndrome Study Group (11\%) and Ramírez-Zamora et al from Spain $(2.9 \%)^{5,6,9}$. Reported mortalities are lower in Italy and Spain which are developed countries with better standards of medical and nursing care. Patients at our institute are mostly poor, illiterate, and ignorant and tend to consult a tertiary centre quite late. Availability of IVIG and ventilator care can be a limitation in an institute with a large patient load. It is often difficult in a general hospital to adhere to the norms and recommendations regarding space criteria per patient and patient to nurse ratio. It is therefore common to see a higher rate of infections and other complications in these patients. The proportion of patients who required ventilation in our study (44.4\%) was almost double that in the study by Farhoudi et al in Iran (22.9\%) which points to late referral and more severe patient profile in our study ${ }^{5}$. The hospital acquired complications seen in our study (Table 2) are also with other chronic disease requiring prolonged hospital stay.

Most of the death in our study occurred within a few days of admission. All these patients were on ventilator support. Most common mode of dying was sudden cardiac arrest which can be attributed to the autonomic disturbance. Tachycardia is common but more serious autonomic nervous system dysfunction may occur, including life-threatening 
arrhythmias and hypotension. Autonomic disturbances are sudden and transient, so that managing and recording such disturbances without proper facilities is a challenge.

In a study by Hiraga et $\mathrm{al}^{12}$ the commonest $\mathrm{NCV}$ type was AMAN (45\%), followed by acute inflammatory demyelinating polyradiculoneuropathy (AIDP) (34\%) and unclassified $(21 \%)$. Recovery was prolonged in AMAN type compared to AIDP but no significant difference in the final outcome of the patients was $\operatorname{seen}^{12}$. Italian Guillain-Barré Syndrome Study Group ${ }^{6}$ showed that evidence of axonopathy may be independently associated with more severe disease variety and less chances of recovery. Thus, some of the studies have shown that AMAN takes more time to recover, but none of the studies has linked NCV study type directly to the mortality in the patients of GBS. In our study, the commonest NCV type was AMAN (50\%) followed by demyelination (37.5\%). In our study 2 out of 6 patients $(33.3 \%)$ with demyelination died but there were no deaths among the other NCV types. Thus demyelination has some association with mortality but more studies are needed to confirm this finding.

The poorer outcome of Guillain-Barre syndrome in older patients has been reported by the Italian Guillain-Barré Syndrome Study Group. This could be due to due to poor axonal outgrowth and regeneration and less effective re-myelinisation as suggested by the Italian Guillain-Barré Syndrome Study Group ${ }^{6}$. In our study there were no deaths in the 2-5 year age group, all deaths occurring in the 612 year age group. Quadriparesis at the time of admission was associated with a $33.3 \%$ mortality compared to paraparesis which was not associated with any mortality. The main limitation of our study was the mall sample size. Thus, all the findings need verification in a larger sample.

\section{Conclusions}

In the study carried out in a tertiary care centre in Gujarat, India, antecedent infection was seen in $38 \%$ of patients. There was a $22 \%$ mortality and demyelination NCV study was seen in $50 \%$ of the expired patients. The prognosis was poorer in the older age groups. Patients with quadriparesis had a poorer prognosis than those with paraparesis.

\section{References}

1. Hahn AF. Guillain-Barré syndrome. Lancet 1998; 352(9128):635-41.

https://doi.org/10.1016/S01406736(97)123 08-X
2. Rees JH, Thompson RD, Smeeton NC, Hughes RA. Epidemiological study of Guillain-Barré syndrome in south east England. Journal of Neurology, Neurosurgery and Psychiatry 1998; 64(1):74-7.

https://doi.org/10.1136/jnnp.64.1.74

3. Yuan CL, Tsou HK, Wang YJ, Tsai CP. Guillain-Barré syndrome: a retrospective, hospital-based study. Zhonghua Yi Xue Za Zhi (Taipei) 2002; 65(11):540-7.

4. Rocha MSBS, Carvalho AA, Lima UW. Epidemiologic features of Guillain-Barré syndrome in. São Paulo, Brazil. Arq Neuropsiquiatr 2004; 62:33-7.

https://doi.org/10.1590/S0004282X20040 00100006

PMid: 15122430

5. Farhoudi M, Ayromlou H, Bazzazi AM, Shadi FB, Golzari SEJ, Ghabili K, et al. Time frequency of Guillain-Barre Syndrome in Northwest of Iran. Life Science Journal 2013;10(1):223-5.

6. Italian Guillain-Barré Syndrome Study Group. The prognosis and main prognostic indicators of Guillain-Barre syndrome: A multicentre prospective study of 297 patients. Brain 1996; 119:2053-61. https://doi.org/10.1093/brain/119.6.2053

7. Van Koningsveld $\mathrm{R}$, van Doorn PA, Schmitz PI, Ang CW, van der Meché FG. Mild forms of Guillain-Barré syndrome in an epidemiologic survey in The Netherlands. Neurology 2000; 54(3):620-5. https://doi.org/10.1212/WNL.54.3.620

PMid: 10680793

8. Jacobs BC, Rothbarth PH, van der Meché FG, Herbrink P, Schmitz PI, de Klerk MA et al. The spectrum of antecedent infections in Guillain-Barré syndrome: a case-control study. Neurology 1998; 51(4):1110-5. https://doi.org/10.1212/WNL.51.4.1110

PMid: 9781538

9. Ramírez-Zamora M B-GC, Alas-Valle DA, Vergara-Galán PE, Ortez-González CI. Guillain-Barre syndrome in the paediatric age: epidemiological, clinical and therapeutic profile in a hospital in El Salvador. Revista de Neurologia 2009; 48(6):292-6.

PMid: 19291652 
10. Taly AB, Gupta SK, Vasanth A, Suresh TG, Rao U, Nagaraja D, et al. Critically ill Guillain-Barré Syndrome. Journal of the Association of Physicians of India 1994;42(11):871-4.

PMid: 7868487

11. Sarkar UK, Menon L, Sarbapalli D, Pal R, Zaman FA, Kar S, et al. Spectrum of Guillain-Barré syndrome in tertiary care hospital at Kolkata. Journal of Natural Science, Biology and Medicine 2011; 2(2): 211-5.

https://doi.org/10.4103/0976-9668.92320

PMid: 22346239 PMCid: PMC3276017

12. Hiraga A, Mori M, Ogawara K, Kojima S, Kanesaka T, Misawa S, et al. Recovery patterns and long term prognosis for axonal Guillain-Barré syndrome. Journal of Neurology, Neurosurgery and Psychiatry 2005; 76(5):719-22.

https://doi.org/10.1136/jnnp.2004.051136

PMid: 15834034 PMCid: PMC1739613 